\title{
Research on the Premise and Path of Catching the Theme of Educational Creation
}

\author{
Yan Zhang \\ Department of English Teaching, ZaoZhuang University, Shandong, 277160, China
}

Keywords: Premise; Path; Theme of Educational Creation

\begin{abstract}
Education writing course is to analyze the successful experience or failure lessons in daily education and teaching, to explore the essence behind it, and then to elaborate on their own unique insights and compose a written topic around certain themes. Common forms of Education writing course include papers, experience summaries, cases, reflections, essays, and so on. Education writing course is an important way to refine educational thoughts, sublimate educational wisdom, and accelerate teacher growth. So, how to improve the level of educational writing? First of all, there must be a valuable writing theme. Only by capturing valuable writing themes can it be possible to write valuable educational articles. So, what are the preconditions for capturing valuable educational writing themes? What are the ways? The author combines his many years of educational writing practice, talks about a few rough ideas, and shares with everyone.
\end{abstract}

\section{Introduction}

Educational writing can sort out your own teaching ideas and conduct in-depth analysis and thinking. For example, our school conducts educational writing on the theme of "student case tracking", which encourages teachers to study students and teaching mathods from the perspective of education. "Student case tracking" is a good form for teachers to reflect on educational practice. Teachers insist on accumulating cases of student growth records, which can greatly increase their own experience accumulation, accelerate the pace of professional growth, and also promote the growth of students. Through a period of "student case tracking", when students have problems, many teachers have begun to deeply reflect on their education and teaching behavior. Through the "student case tracking", teachers began to pay attention to each child with the eyes of the researchers. When we look at each student from different families and different personalities in the eyes, we have already paid attention to every child has taken a solid step [1]. The theme writing such as "Student Case Tracking” can record the difficulties, confusions and problems encountered by the teachers themselves in the practice of education and teaching, as well as the methods and methods of improving the results and feelings after the work, so as to continuously improve themselves.

\section{The Premise of Capture}

\subsection{Have a sense of refinement.}

Refining consciousness means that teachers should always reflect on new problems, new methods, new ideas, and new gains in education and teaching practice, and strive to explore the connotations of these new problems, new methods, new ideas, and new harvests, and summarize the implications of them.

For example, when teaching different learning materials or different organizations of the same material, the process of students' learning is completely different. The rational selection and use of learning materials is an important prerequisite for improving the efficiency of classroom teaching. To this end, the author cuts people from the perspective of the relationship between learning materials, and repeatedly analyzes and classifies the accumulated mathematical learning materials, and finally extracts the theme of "Major types and connotations of mathematical learning materials" and writes a written article[2]. It can be seen that refining consciousness is a necessary prerequisite for capturing valuable writing themes. 


\subsection{Be professionally sensitive.}

Only by maintaining a strong sensitivity to your own work can you consciously pay attention to all the educational and teaching phenomena related to your own work, especially the attention to some subtle changes in your own work, and these subtle changes are precisely The subject of value writing, if captured in time and written in writing, is often a good article.

Educational writing is a record of thinking

\subsection{There must be a concept of small and big.}

To see the big and small, is to capture the small writing theme of the incision, through the deep excavation of these small themes, to show the rich content of education and teaching, thus broaden their educational horizons. In fact, good educational writing themes are hidden in many small educational and teaching phenomena that require us to capture and refine. Therefore, teachers should be keen to capture some small puzzles, small thoughts, and small problems in daily education and teaching, and carefully sort out these small puzzles, small thoughts, and small problems, and extract some valuable writing themes.

For example, when a teacher is teaching "sharp angles and obtuse angles", the teaching ideas of the design are very characteristic, but the teaching time is too late. In this regard, the author conducted a careful analysis and found that the main reason for this phenomenon is that the teaching starting point is low, which affects the main content teaching. Because the logical starting point of the acute angle and the obtuse angle is a right angle, it is more appropriate to start from the right angle, but the coach starts to cut people from the corner, and takes a certain teaching time from the corner to the right angle. To this end, the coaches made appropriate adjustments according to the author's intentions, and the results were successful. Inspired by this, the author has deeply thought about the practical problem of teaching starting point, and found that the choice of teaching starting point should be considered from the two points of logical starting point and realistic starting point, so I will extract the starting point of how to accurately grasp the mathematics learning of students. The theme of this book was written and published. The results were published in the "Teaching Materials Teaching Research" and later reprinted in the full text of the "Primary School Science and Education" magazine sponsored by the Renmin University of China. It can be seen that the idea of establishing a small and big idea is the basic premise of capturing valuable writing themes [3].

\section{The Capture Route}

\subsection{Teaching and grooming.}

It is to consciously record and evaluate some wonderful teaching pieces in daily teaching practice, and then sort out these records and comments in a timely manner, and extract the writing theme according to the results of combing. Because these themes are extracted from their own teaching practices, they are more original and practical, and often resonate with other teachers.

\subsection{Task refinement.}

On the basis of earnestly completing the teaching and research tasks arranged by the school or higher-level units, the results of their tasks are collated and reflected, and the targeted writing themes are captured and refined. This kind of theme comes from real teaching and research activities. If you can write a written article, it often has a strong guiding role [4].

In a sense, teachers' reading is more important than writing. Because writing is a manifestation of the teacher's own experience, it is the teacher's external wisdom, and the role of the teacher's own concept of renewal and literacy is limited. Reading is the absorption and accumulation of teachers' experience of others. It is an important way for teachers to internalize the good ideas and experiences of others. The renewal of the teacher's concept and the improvement of literacy are more dependent on reading this form.

\subsection{Inspired by experts.}

Experts' wonderful lectures or reviews often lead us to some fleeting feelings, thoughts, and revelations, which often lead to fierce conflicts in our hearts, which make us strongly resonate, which makes us suddenly clear. If you suddenly look at the ideas or events that excite us, you can often capture novel writing themes. 
Because this view or event is often a good yearning for education, it is forward-looking, and the writing theme formed on this basis is of great value.

\subsection{Research on the subject.}

Research on topics is an important part of education and research, and an important way for teachers to grow professionally. Because the research of the subject is a task that must be completed carefully within the stipulated time, the researcher has certain administrative and academic pressures. In order to accomplish this task, the researcher is often more active and can calm down and conduct a series of related research around the subject. Due to the rich content of the subject, there are often many new discoveries and new gains in the research process. If these new discoveries and new harvests can be sorted out, many valuable writing themes can be captured and refined. If you can write these writing themes, it will increase the amount of research, and it will also promote the rapid education of researchers.

\subsection{Test paper analysis.}

After the test, the test paper not only saves the scores reflecting each student's knowledge and ability level, but also preserves a large amount of valuable information that can be used to study the students' learning and teachers' teaching. Therefore, every teacher should pay attention to the examination paper analysis. Through the examination paper analysis, we can know the mastery of each part of the knowledge of the knowledge, which knowledge is well mastered, which knowledge is not enough, find out the common problems of most students who have lost points, and thus consciously adjust their teaching; Analysis, you can understand the gap between your own teaching and the students' learning, you can understand the mistakes and biases in your teaching, and thus improve your teaching in a targeted manner. The above common problems, mistakes and biases, a little refinement is a very practical writing theme, such as writing a written article, often get the positive response of other teachers [5].

In order to reduce the difficulty of teaching for a while, in order to highlight the teaching ideas of the textbook - using the equation to answer, but neglecting to let students use the integrated formula to answer this problem-solving idea, which leading to the emergence of this unexpected phenomenon. It can be seen that the author is not a practitioner who thoroughly "teaches with teaching materials" and has the phenomenon of teaching textbooks. Therefore, the author captures and refines the teaching materials through the analysis and thinking of this lesson. It can be seen that paper analysis is also an effective way to capture valuable writing themes.

\subsection{Disciplinary analysis.}

Different disciplines have different teaching characteristics. If you can analyze the teaching process from the characteristics of the subject teaching, you will capture many valuable writing themes. For example, the "Mathematics Curriculum Standards" proposes that "through the mathematics learning in the compulsory education stage, you can acquire the important mathematical knowledge (including mathematical facts, mathematical activity experience) necessary for adapting to future social life and further development, as well as basic mathematical thinking methods and necessary applications. ". It can be seen that it is an important goal of mathematics teaching to allow students to acquire basic mathematical thinking methods. The results have achieved some practical results. These effects have prompted the author to reflect on the teaching practice, capture and extract some valuable writing themes and write in time.

\subsection{Listen to the lessons.}

Listening to classes often helps teachers learn from each other, learn from each other's strengths, improve together, and advance together. In fact, every open class embodies the hard work of coaches and instructors. Their teaching ideas are often the concentrated expression of their recent teaching ideas and strategies. Therefore, the teachers who participate in the lectures must be serious. Only in this way can we draw useful teaching experience from it. In fact, the teaching ideas of the coaches and the teaching ideas presupposed by the lecturers often have certain conflicts. If the lecturers can consciously analyze these conflict points, they can quickly improve their education and teaching level. Capturing novel writing themes, if you can write a written article, is a valuable teaching resource. 


\subsection{Case study}

The educational teaching case not only records education and teaching behavior, but also records the thoughts, emotions and inspirations that accompany the behavior; not only shows the problems, contradictions and confusions encountered by teachers in education and teaching activities, but also reflects the resulting ideas, ideas and countermeasures. Therefore, teachers should often carefully analyze the wonderful educational teaching cases that they have experienced and observed, draw useful lessons from them, and promote the most exciting ideas to the writing theme.

For example, after listening to the "tree planting problem" taught by the scorpion teacher, the author feels that the teacher's application of modeling ideas is in place. In this regard, the author carefully analyzed this lesson, and finally extracted the theme of "small step advancement: effective strategy for mathematical modeling" It can be seen that case analysis is an important way to capture valuable writing themes and an important way to conduct educational research.

\subsection{Read the revelation}

Education and teaching journals often display the latest teaching concepts, teaching ideas and teaching strategies. Frequent reading of educational and teaching journals often has some unexpected gains. In particular, some of the more excellent articles often give the reader a bright feeling, even a slap in the face. If you can read these fascinating and succinct articles, the readers will often have some impulses. These ideas or content that make readers impulsive are often valuable writing themes, such as timely capture and writing. , often has a strong guiding role.

\subsection{Management experience}

Education management is an important task that every teacher must face every day. In a sense, the level of teacher management will directly determine the quality of education and teaching. Therefore, each teacher will always manage his work objects in a way that he is good at. With the increase in education and teaching experience, its management methods have become increasingly mature. If you can sort through these more mature methods, you can capture some valuable writing themes.

Therefore, teachers' educational writing can have different value pursuits, but even in order to meet the requirements of school performance appraisal or teacher title appraisal, education writing should face the true problems encountered by teachers themselves, and write education. This kind of educational writing based on the true problems encountered by teachers themselves can not only effectively avoid the hollow writing of problem distortion, but more importantly, it can enable teachers to re-examine and understand their own education and teaching with a reflective and research perspective. The way of teaching and teaching by oneself allows teachers to see the mystery of education and teaching in educational writing, enjoy the unique happiness of teachers, and enrich and plump the spiritual world of teachers. For example, in class management, or in time order, think about daily, weekly, monthly, and even school year work, or think about the management of classrooms, dormitories, canteens, etc. in the order of space, or think in terms of topics. Students' thoughts and behaviors, class cadre construction, study style, class style and other routine work, or use their own quality as a clue to think about the gains and losses, success or failure of work. Thinking about these real problems, and having personal practice and sentiment, and then writing what you have done and feelings into words, educational writing will continue to emerge.

\section{Conclusion}

In short, the ups and downs in classroom teaching, the joys and sorrows in student management, the meditations during the preparation of classes, and the unique findings in correcting assignments are the sources of writing themes. If teachers can calm down and seriously observe, think, experience, reflect, analyze, and refine, they will be able to capture valuable writing themes. If they can write a written article, they will be valuable teaching resources and spiritual wealth, which will help everyone to share. 


\section{References}

[1]. Li Runzhou. Value Identification and Generation of Educational Issues[J]. Educational Academic Monthly, 2011(3): 3-7.

[2]. Zhai Weihua. To educate and research and lead educational writing[J]. Teacher Training for Primary and Secondary Schools, 2013(11): 28-29.

[3]. Yu Xiaogang. Because of the theory, Naiwen-an overview of teacher's thesis writing and "The 15th Excellent Teacher Paper Selection Activity in Sichuan Province"[J]. Sichuan Education, 2014(10):39-43.

[4]. Zhou Yimin. "I" and a discourse [J]. Jiangsu Education, 2013 (4): 62.

[5]. Zheng Liping. Enjoy the unique happiness of the class teacher in the growth [J]. Friends of the class teacher, 2009 (8): 9-13. 